\title{
The use and effectiveness of the eLib subject gateways: a preliminary investigation
}

\author{
MORAG MACKIE and PAUL F. BURTON
}

\begin{abstract}
Internet subject gateways were set up under the Electronic Libraries Programme (eLib) in order to address some of the problems of searching the Internet which have been identified by information professionals, i.e. locating relevant, good quality information. This preliminary study examines the extent to which academics in two universities use three eLib subject gateways (EEVL,OMNI and SOSIG). The results are generally encouraging for the eLib programme, but it is necessary for the gateways to be more effectively promoted. The study also found that academics do not have the same misgivings about the general search engines as the information professionals and seem to use them more readily than the gateways.
\end{abstract}

\section{Introduction}

Following the report of libraries in UK Higher Education Institutions chaired by Sir Brian Follett, a variety of projects were set up under the eLib Programme to maximise the benefits of the Internet to academics in a number of ways. One of the most "stable and coherent" of these has been the establishment of Internet subject gateways, which have already been described as "one of eLib's success stories".,1,2 Three of these gateways (Edinburgh Engineering Virtual Library (EEVL), the Organising Medical Networked Information gateway (OMNI), and the Social Science Information Gateway (SOSIG)) were investigated in order to establish the extent to which they are used by their intended recipients (the academic community) and whether they are perceived to be effective in locating quality information.

The Internet as a whole is not well organised and information retrieval can often be a difficult and frustrating process: "the sheer enormity of information available and the corresponding lack of organisation of this information can prove an effective barrier to potential users". ${ }^{3}$ Furner adds that "its size, heterogeneity and inconstancy pose particular problems for those whose concern it is to locate and retrieve precisely the information they require at a given time". ${ }^{4}$ If access to networked information is to be an effective strategy in exploiting information technology as well as off-setting resource shortages in higher education, improvements in the way in which information is accessed on the Internet are required. Internet subject gateways are concerned both with taking advantage of the opportunities offered by the Internet, and also acting as one possible solution to the problem of information retrieval and quality control

Program, vol. 33, no. 4, October 1999, pp. 327-337

Aslib, The Association for Information Management

Staple Hall, Stone House Court, London EC3A 7PB

Tel: +44 (0) 171903 0000, Fax: +44 (0) 1719030011

Email: pubs@aslib.co.uk,WWW: http://www.aslib.co.uk 
All rights reserved. Except as otherwise permitted under the Copyright, Designs and Patents Act 1988, no part of this publication may be reproduced, stored in a retrieval system, or transmitted in any form or by any means, electronic, mechanical, photocopying or otherwise without the prior written permission of the publisher.

Program vol. 33 no. 4

which will be more effective than other solutions such as search engines (which lack discrimination), metadata (which would have to be added by authors), classification schemes, catalogue entries or the use of PICS (Platform for Internet Content Selection) to set quality selection criteria. ${ }^{5-10}$

\section{The subject gateway approach of the eLib programme}

The eLib gateways provide an organised access point to subject-specific information on the Internet for the higher education and research community. They are seen as "a gathering place of discipline specific resources" 11 which distinguishes them from search engines. Moffat describes the establishing of the gateways as "a process of identification, filtering, description, classification and indexing before they are added to a database which is freely available via the World Wide Web". ${ }^{12}$ Selected resources must meet a number of criteria applied by a librarian or academic, which ensure that only high quality, relevant resources are included in the database,$^{13}$ and this high level of human input is another important feature which distinguishes the subject gateways from search engines.

The gateways do not "aim to replace other available tools", but "hope to offer a complementary service which will provide a targeted and focused area for resource discovery for the ... academic community". ${ }^{12}$ Each of the gateways under consideration has its own criteria for resource selection and description and each uses a classification scheme. Contributions to the resource database are made by project staff, volunteers and trusted information providers, and each gateway offers its users the opportunity to suggest resources for inclusion. Current details of the three gateways examined in this study, including the sizes of their databases, can be found at their respective WWW pages. ${ }^{14,15,16}$ Techniques developed for assessing resources for these services are described. ${ }^{17,18,19}$ Staff must be able to establish the context of a resource, i.e. Who is responsible for it? Who is the intended audience? How reputable is the information provider? and so on. One of the problems of the Internet, however, is that it is often difficult to establish such facts. Resources must also be evaluated in terms of their content, i.e. accuracy, availability, currency and the frequency and regularity of updating. Context and content are particularly important areas of evaluation, as it is these which set the gateways apart from search engines. Resources are also examined in the light of their design and ease of access. Comprehensive coverage of criteria for evaluating networked resources is given by Cooke. ${ }^{20}$

Selected and evaluated resources are then given a description similar to a catalogue record. SOSIG records, for example, contain information such as title, description, keywords, language and URL (Uniform Resource Locator), plus a classification code. Resource descriptions are particularly important, as they enable users to make an informed decision on the value of the resource. EEVL resources are described in a short paragraph which highlights the important features to be found at the site. OMNI records basic information on the 
All rights reserved. Except as otherwise permitted under the Copyright, Designs and Patents Act 1988, no part of this publication may be reproduced, stored in a retrieval system, or transmitted in any form or by any means, electronic, mechanical, photocopying or otherwise without the prior written permission of the publisher.

title, description, URL, MeSH (Medical Subject Headings) keywords and an NLM (National Library of Medicine) classification code. Additional information is sometimes provided about such areas as publishers and contact details for resource administrators.

The gateways thus enable users to search by keyword, to browse through a list arranged by subject, and to read resource descriptions, allowing them to decide on the relevance of a resource. Staff also check that existing resources are still suitable for inclusion. Records for resources which have changed, e.g. in content, may require editing to reflect these changes. If, however, a resource has lost its value, e.g. in terms of currency or reliability, it is removed from the database. Because of the tendency of Internet resources to move location or to disappear altogether, the gateways make use of automated link checking programs to identify any broken links.

The most significant disadvantage (and the area most often commented upon by workshop participants) is the lack of resources covered when compared to search engines. Dong and Su commented that "the limitations in their coverage of resources and frequency of updating have restricted them from becoming the main access tools for the Internet." ${ }^{21}$ Poulter has pointed out that "the two biggest problems for subject directory search engines are keeping up with the ever increasing flow of new WWW pages ..., and preserving an ordered browsable structure as the range of subjects continually expands"22 while Janes and Rosenfeld suggest that subject gateways "are useful as starting points, but go little further and may or may not be able to scale to cover larger chunks of the networked world." 23

However, the subject gateways do not set out to compete with search engines in terms of the number of resources covered: SOSIG's aim is "to be a selective rather than comprehensive collection, pointing only to high quality Internet information resources."

\section{Evaluations of the gateways: methodology}

As part of an MSc programme of research in the Department of Information Science, University of Strathclyde, questionnaires were sent to a stratified sample of academic staff at two universities during 1997. As the study was concerned with three different gateways, questionnaires were sent to staff working in three separate faculties in each university - engineering, biomedicine and social science. Each faculty in each university received 20 questionnaires, giving a possible 40 responses for each gateway.

For each faculty, two departments were chosen at random from those departments which had more than ten members of staff (to ensure sufficient people to survey), and whose members of staff were listed on the departmental web page (which would be more up-to-date than the University calendars). Twelve departments were thus selected, covering the disciplines of electrical, electronic, mechanical and civil engineering, pharmaceutical sciences, pharmacology, medicine, forensic science, economics, politics, and sociology. 
(C) Aslib, The Association for Information Management.

All rights reserved. Except as otherwise permitted under the Copyright, Designs and Patents Act 1988, no part of this publication may be reproduced, stored in a retrieval system, or transmitted in any form or by any means, electronic, mechanical, photocopying or otherwise without the prior written permission of the publisher.

Program vol. 33 no. 4

Table 1. Respondents by academic grade

\begin{tabular}{lr}
\hline Professor & $23 \%$ \\
Reader & $5 \%$ \\
Senior Lecturer & $33 \%$ \\
Lecturer & $20 \%$ \\
Research/doctoral student & $14 \%$ \\
Other & $5 \%$ \\
\hline
\end{tabular}

The population of each department was then stratified by academic grade and survey respondents were then chosen randomly from within each of the academic grades of Professor, Reader, Senior Lecturer, Lecturer, Research/ doctoral student and an 'other' group. Inconsistencies in listings by departments of research staff meant that, although the questionnaire was submitted to a number of doctoral students, the majority of those to receive the questionnaire were lecturers, senior lecturers, readers and professors: the total population surveyed came to 120 . Sixty-four usable questionnaires, a response rate of over $53 \%$, were returned, though the response rate differed slightly between the gateways - EEVL and SOSIG both had 23 of 40 responses $(57.5 \%)$, whereas OMNI had 18 from 40 responses $(45 \%)$.

Seventy-three per cent of respondents were male: Table 1 shows the academic grade of respondents. There were no significant differences between academic grades in their use of the gateway relevant to their discipline.

\section{Results}

Overall, only 18 out of the 64 respondents had used any of the subject gateways, i.e. less than $30 \%$. The results of this study should therefore be regarded as tentative and will require corroboration by a larger study covering more institutions. This low figure suggests that the gateways have still to make an impact on academic staff. SOSIG had the highest number of users - 10 from $23(43.5 \%)$, while EEVL had six $(26 \%)$ and OMNI had two from 18 users $(11 \%)$. We must remember, however, that SOSIG is the longest established gateway, which may explain the higher number of users. One-third of users were aged $40-49$, and $60 \%$ of users were between $30-49$. One-third of those who used the gateways were lecturers, senior lecturers and professors accounted for $22 \%$ each, research/doctoral students $17 \%$, and readers $6 \%$. It seems that there is no typical gateway user, as overall the respondents who had used the gateways were fairly widely spread in terms of age, sex and academic status.

Respondents who had not used the subject gateways were asked if they were aware of their existence. Of the 46 people in this category, 15 were aware of the gateway relating to their subject area, while the remaining 31 were not. Thus, of all the respondents, just over $50 \%$ were at least aware that the subject 
(C) Aslib, The Association for Information Management.

All rights reserved. Except as otherwise permitted under the Copyright, Designs and Patents Act 1988, no part of this publication may be reproduced, stored in a retrieval system, or transmitted in any form or by any means, electronic, mechanical, photocopying or otherwise without the

October 1999 prior written permission of the publisher.

eLib subject gateways

Table 2. Source of gateway awareness

\begin{tabular}{lr}
\hline Browsing the Internet & $32 \%$ \\
Other & $28 \%$ \\
Colleague & $17 \%$ \\
Unsure & $17 \%$ \\
Library & $6 \%$ \\
\hline
\end{tabular}

gateways existed: conversely, these figures suggest that not as many academics are aware of the gateways as might have been hoped for.

The 18 respondents who had used the gateways first became aware of them in a variety of ways, shown in Table 2 .

The 'Other' category included publicity material from the relevant gateway (SOSIG) and participation in an EEVL seminar at their institution's library. It is hard to say what would be the most effective method of raising awareness of the gateways, since the possible sources were used by relatively large numbers of respondents. However, as only $6 \%$ of respondents recalled discovering the gateways through their institution's library, it seems that this may not be the best way of targeting academics: a direct approach may be more successful.

Half of the gateways' users indicated that they used them less than once per month. This relatively low frequency of use may be due to the fact that academics use the gateways for very specific purposes, and only when a specific query arises. Twenty-two per cent of users said that they used the gateways about once a month, and only $11 \%$ reported using the gateways as often as once a week. Further research is required to discover why the gateways are not used on a regular basis and to establish more precise patterns of use, for example what subjects are sought?

Almost two-thirds of users $(61 \%)$ had not received any training or advice on the use of the gateway in question. It is not possible to tell if those who had received training would have used the gateway if they had not been offered it, but the proportion of trained users gives some weight to the theory that use of the gateways is encouraged by attending a training session of some sort. Further research would be needed to support this. Obviously staffing limitations make it difficult for gateway staff to provide training for all potential users. It seems clear that training is a way of getting academics to use the gateways and this concurs with the results of questionnaires distributed by gateway staff at training sessions, which were predominantly positive.

Nearly all respondents replied that the gateways were either "very easy" or "fairly easy" to use, and only one found them "fairly difficult" to use. No respondents found the gateways very difficult to use. This is a particularly encouraging statistic, and indicates that it is unlikely that low usage levels are caused by any difficulty in use.

On the effectiveness of the gateways in locating relevant information, four respondents (22\%) stated that the gateways were an effective tool, while three $(16 \%)$ said that they were not. However, the majority of respondents were less 
All rights reserved. Except as otherwise permitted under the Copyright, Designs and Patents Act 1988 , no part of this publication may be reproduced, stored in a retrieval system, or transmitted in any form or by any means, electronic, mechanical, photocopying or otherwise without the prior written permission of the publisher.

Program vol. 33 no. 4

certain, 50\% replying that the gateways were effective "some of the time". In aggregate, therefore, over $70 \%$ of respondents believed the gateways to be effective tools for searching the Internet at least some of the time. However, it is clear that respondents also had some reservations, and further research is required to provide a better picture and the detail of those reservations. There were no noticeable differences between the gateways.

Users were also asked if they found a subject-based approach to finding information on the Internet useful or not. The responses here were much more clear cut. Two thirds of respondents replied that they did find a subject-based approach useful when compared with general search engines. Twenty-eight per cent of users were uncertain, and only one was definite that a subject-based approach was not useful. This would seem to indicate that one of the most vital aspects of the gateways is appreciated by those who use them, and it substantiates the idea behind the gateways that subject gateways are more useful than similar tools which attempt to encompass all subjects. Interestingly, all 10 SOSIG users believed that a subject-based approach was definitely useful, EEVL users were less convinced, with two thirds being uncertain and the two OMNI users were less certain still, with one replying that a subject-based approach was not useful, and the other uncertain.

When asked how likely they would be to carry out a search on the subject gateways when starting a piece of research, respondents were equally divided, with 50\% replying that they were unlikely to do so, and the other 50\% replying that they were fairly or very likely to do so. The responses here raise interesting questions about specific uses of the subject gateways - an area not covered by this study. One possibility is that they are used to find very specific information, or, as one respondent put it, "to find what you know exists but whose URL you don't - not to carry out fishing expeditions for information". This is certainly an area which would bear further investigation.

The vast majority ( $88 \%$ ) of academics felt that there were no aspects of the gateways which they disliked or felt could be improved. This result supports the findings of the gateways themselves that the only significant complaint which users had was that the gateway databases did not contain enough resources. However, one academic stated "I used EEVL twice to search for information without success - of course this discourages me from using it! General search engines were successful in locating useful information on these subjects". Of course, it is possible that the sites picked up by search engines were not linked to by EEVL because they had not met the necessary evaluation criteria.

It should be noted that a number of answers suggest that some academics are not aware of the differences between subject gateways and search engines. Others are not aware of a difference between search engines and search services such as BIDS. In general, the questionnaire findings suggest that most academics are not particularly sophisticated or knowledgeable in terms of their use and searching of the Internet. This is an important factor as it is likely to have had a bearing upon the answers to many of the questions in this survey. 
All rights reserved. Except as otherwise permitted under the Copyright, Designs and Patents Act 1988, no part of this publication may be reproduced, stored in a retrieval system, or transmitted in any form or by any means, electronic, mechanical, photocopying or otherwise without the

October 1999 prior written permission of the publisher.

eLib subject gateways

Perhaps surprisingly there were few significant differences between those who had received some form of training in the use of the gateways and those who had not. It appears that using the gateways is easy for academics, regardless of whether or not they have received training. Almost equal proportions of the two categories of users found the gateways to be useful "sometimes".

Responses indicated that proportionally more users who had not received training found a subject-based approach useful. On the other hand, when asked how likely they were to carry out a search on the gateways when starting a piece of research, the only academics to reply "very likely" were those who had received training. Overall, then, the provision of training does not appear to make much difference to academics' views of the subject gateways, though we must bear in mind the small number of respondents.

Eighty-six percent of respondents had used other areas of the Internet as a source of information (compared to $28 \%$ who had used subject gateways). It is not, therefore, the case that academics fail to use the subject gateways because they do not use the Internet in the first place. Almost two-thirds of respondents use the Internet at least once a week for research purposes. The subject gateways do not feature highly as a frequently-used tool on the Internet, again suggesting that academics may choose to use them for specific, rather than general, purposes.

The use of search engines on the Internet is also high among academics, as $85 \%$ of respondents used them. It was interesting that three respondents who did use the subject gateways did not use search engines, but as the perceived inadequacy of search engines was part of the impetus for establishing the subject gateways this is not a particularly encouraging figure. More academics need to be made aware of the advantages which the subject gateways offer.

Surprisingly, $72 \%$ of respondents who reported using search engines believed that they were effective in locating information on the Internet: only five academics $(10.6 \%)$ regarded them as definitely not effective. This does not appear to confirm the view of many of those working in the information field that search engines are often ineffective, and have many associated problems. One possibility is that unlike librarians, academics do not think of the Internet in terms of existing methods of searching for information, and therefore do not see the inadequacies. Of course, it is likely that few academics have knowledge of how searching on the Internet works, or of the mechanisms behind search engines, and therefore have no reason to consider how searching and quality issues might be improved. This is an area which requires substantial further research, and thus any conclusions reached here are merely based upon informed speculation. However, research carried out by Nicholas et al on the Internet use by journalists, concluded that "the much touted Internet issues - lack of quality, slow response times and the all-engulfing information flood - barely raise a stir with the end user. Similarly, end-users are either oblivious or blasé about Internet search facilities." There was a general feeling that "too much misplaced criticism, too much negativity and too much problem identification" was to be found on the part of information professionals when considering the Internet. ${ }^{24}$ It would appear that 
All rights reserved. Except as otherwise permitted under the Copyright, Designs and Patents Act 1988 , no part of this publication may be reproduced, stored in a retrieval system, or transmitted in any form or by any means, electronic, mechanical, photocopying or otherwise without the prior written permission of the publisher.

Program vol. 33 no. 4

information professionals are overly concerned with supposed problems which are not, in fact, identified by those whose are using the Internet. It might even be suggested that information professionals are deciding what is good for people, without consulting them about their needs and wishes. However, information professionals' concern should be with providing what is best for their users, despite the fact that those users may not be aware of the problems associated with the information finding tools that they are currently using. Perhaps the solution lies in keeping users better informed about search engines, how they operate, and how some methods of searching the Internet are more effective than others.

The survey respondents were also given the opportunity to comment upon any of the areas raised in the questionnaire, and the general consensus of these is that the Internet has many advantages for academics, and is proving to be a valuable tool. The comments specific to the subject gateways reflect the minor concerns which users have. It is significant that no respondents used this space to criticise the Internet, or complain about the difficulty of finding information on it or the quality of that information.

\section{Some tentative conclusions}

We found that fewer than $30 \%$ of our population had used the gateways but those who have, do find them useful to some extent. Several indicated that they had carried out searches which had produced no results, but whether this was due to the relatively small size of the database searched or their searching techniques was not clear.

The staff of the gateways have worked hard to publicise them with limited resources. It is clear that more work is required in this area, though the academics surveyed did not suggest any significant improvements which could be made. It is equally difficult to establish whether the subject gateways are an effective solution to the problems of locating high quality relevant information on the Internet. The results of our study suggest that the subject approach is appreciated.

The gateways have been very active in carrying out evaluations, both in the form of surveys and follow-up questionnaires to those who have attended training workshops, and by inviting experts to assess and report on the progress and success of the gateways. Staff themselves have also been involved in regular evaluations of progress. A good deal of valuable work has already been carried out in the evaluation of the gateways, but it was not possible to make a direct comparison with our results, as the circumstances under which the surveys were carried out were not the same in several important respects. Surveys carried out by EEVL, OMNI and SOSIG have generally been based upon the views of those who have attended workshops and training sessions. This is the probable explanation of why our findings, on the whole, were less favourable than those of the gateways. Some indications of the gateway providers' evaluations, etc. can be found in the annual reports and other publicly available documents. ${ }^{25,26} \mathrm{~A}$ recent evaluation of EEVL has been carried out by Kemp 
All rights reserved. Except as otherwise permitted under the Copyright, Designs and Patents Act 1988, no part of this publication may be reproduced, stored in a retrieval system, or transmitted in any form or by any means, electronic, mechanical, photocopying or otherwise without the

October 1999 prior written permission of the publisher.

eLib subject gateways

and Davenport ${ }^{27}$, though they were primarily concerned with what happens when users actually encounter EEVL.

The aim of our survey was to provide a preliminary, independent snapshot of academics' attitudes to the gateways. The majority of academics do not use the subject gateways, and many have not heard of them at all. Some academics are very positive about the subject gateways; many are, as yet, undecided about their effectiveness. One unexpected finding was that the vast majority of respondents regarded search engines as an effective tool for searching the Internet. The small number of gateway users in our study found it difficult to suggest any improvements which could be made to the gateways. The findings of the gateway evaluations themselves confirm that users have not tended to make many discouraging comments about the gateways. Thus, while it is important to continue to improve and expand the gateways, it is perhaps even more important to consider how best they can be more effectively publicised to academics.

Perhaps the most encouraging finding of our research was that a large number of academics use the Internet frequently. It confirms that academics are willing to use the Internet as part of their teaching and research activities, and thus that they are more likely to be receptive to concepts such as electronic journals, digitised resources and the idea of the virtual library developed through the eLib programme. The main impediment to this is likely to be the fact that many academics feel that they require more training in the use of the Internet before they would be willing to use it alongside other, more familiar, information-finding tools.

Gateways are needed to improve the effectiveness of Internet searching, though this is not wholly borne out by the results of this limited survey. It is recommended that greater publicity is required to raise awareness among academics of the gateways and thereby develop greater levels of use. Further research could then be undertaken to assess both the effectiveness of searching through the gateways, and the attitudes of users towards them. Perhaps the real impact of the subject gateways and of eLib in general cannot yet be determined. Green has argued that "even when all of the projects have come to the end of their lives - and it is to be hoped that many will continue as services long after the initial funding runs out - it will be a long time before final assessments can be made". ${ }^{2}$

\section{References}

1. Tavistock Institute. Evaluation of the Electronic Libraries Programme. Policy mapping study: the set-up, operation and content of the Electronic Libraries Programme, 1996. http://www.ukoln.ac.uk/services/elib/papers/ tavistock/policy-mapping/

2. A. Green. Towards the digital library: how relevant is eLib to practitioners? The New Review of Academic Librarianship, vol. 3, 1997, p. 41. 

prior written permission of the publisher.

3. D. Hiom, and L. Huxley. Using SOSIG to support social science teaching and research. Paper presented at the Essex96 Conference, Colchester, Essex, UK: 1-5 July 1996. http://sosig.ac.uk/training/essex96/paper.html

4. J. Furner. IR on the web: an overview. Vine, no. 104, 1996, pp. 3-13.

5. A. Anagnostelis, A. Cooke and A. McNab. Thinking critically about information on the web. Vine, no. 104, 1996, pp. 21-27.

6. C.J. Armstrong. Metadata, PICS and quality. Online and CD-ROM Review, vol. 21, no. 4, 1997, pp. 217-222.

7. M. Dekkers and L. Dempsey. Stabilising data about data. Library Technology, vol. 3, no. 2, 1998, p. 35.

8. T. Koch et al. The role of classification schemes in Internet resource description and discovery, 1997. http://www.ukoln.ac.uk/metadata/ classification/class_l.htm

9. W. Britten. Building and organizing Internet collections. Library Acquisitions: Practice and Theory, vol. 19, no. 2, 1995, pp. 243-249.

10. B. Landesman. Keeping the Jell-O nailed to the wall: maintaining and managing the virtual collection. The Serials Librarian, vol. 30, no. 3/4, 1997, pp. 137-147.

11. R. Bradshaw. Introducing ADAM: a gateway to Internet resources in Art, Design, Architecture and Media. Program, vol. 31, no. 3, 1997, pp. 251-266.

12. M. Moffat. An EEVL solution to engineering information on the Internet. Paper Presented at the Aslib Electronics Group 38th Annual Conference 15th-17th May, 1996. http://www.eevl.ac.uk/paperl.html

13. About SOSIG. http://www.sosig.ac.uk/about.html

14. Edinburgh Engineering Virtual Library (EEVL). http://www.eevl.ac.uk

15. Organising Medical Networked Information (OMNI). http://www.omni. ac.uk

16. Social Science Information Gateway (SOSIG). http://www.sosig.ac.uk

17. R. Macleod, L. Kerr and A. Guyon. The EEVL approach to providing a subject based information gateway for engineers. Program, vol. 32, no. 3, 1998, pp. 205-223.

18. OMNI guidelines for resource evaluation. 1998. http://www.omni.ac.uk/ agec/evalguid.html

19. Evaluating Internet resources for SOSIG. http://www.sosig.ac.uk/ desirelecrit.html

20. Alison Cooke. A guide to finding quality information on the Internet: selection and evaluation strategies. London: Library Association Publishing, 1999.

21. X. Dong and L.T. Su. Searching engines on the World Wide Web and information retrieval from the Internet: a review and evaluation. Online and CD-ROM Review, vol. 21, no. 2, 1997, pp. 67-80.

22. A. Poulter. The design of World Wide Web search engines: a critical review. Program, vol. 31, no. 2, 1997, pp. 130-143. 
(C) Aslib, The Association for Information Management.

All rights reserved. Except as otherwise permitted under the Copyright, Designs and Patents Act

1988 , no part of this publication may be reproduced, stored in a retrieval system, or transmitted in any form or by any means, electronic, mechanical, photocopying or otherwise without the

October 1999 prior written permission of the publisher.

23. J.W. Janes and L.B. Rosenfeld. Networked information retrieval and organisation: issues and questions. Journal of the American Society for Information Science, vol. 47, no. 9, 1996, pp. 711-715.

24. D. Nicholas et al. The Internet: the users' story. Managing Information, vol. 4, no. 9, 1997, pp. 28-31.

25. M. Moffat. A glimpse at EEVL's evaluation. Ariadne, no. 8. http://www. ariadne.ac.uk/issue8/eevl-evaluation/intro.html

26. Annual report to eLib for the period from 1st August 1996 to 31 st July 1997. http://www.eevl.ac.uk/annrep2.html

27. R. Kemp and E. Davenport. A user-centred qualitative evaluation of the EEVL service: summary. 1998. http://www.eevl.ac.uk/evalsumm.html

\section{Authors \\ Morag Mackie, Student, and Paul F. Burton, Senior Lecturer, Department of Information Science, University of Strathclyde, Glasgow G1 1XH, Scotland. E-mail:paul@dis.strath.ac.uk}

